\title{
Implementing decision support for natural resource management agencies - the SCaRPA experience
}

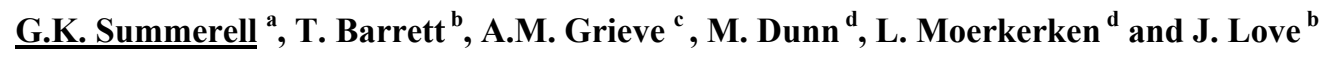 \\ ${ }^{a}$ NSW Office of Environment and Heritage PO Box 5336 Wagga Wagga NSW 2650 \\ ${ }^{b}$ NSW Office of Environment and Heritage PO Box 402 Armidale 2350 \\ ${ }^{c}$ Scientific \& Environmental Services Pty Ltd West Pennant Hills NSW 2125 \\ ${ }^{d}$ Murrumbidgee CMA PO Box 5224, Wagga Wagga NSW 2650 \\ Email: gregory.summerell@environment.nsw.gov.au
}

\begin{abstract}
A spatially based decision support system developed for use in guiding investment by

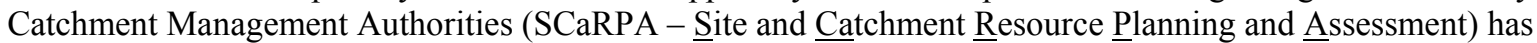
been trialled during the past three years with the Murrumbidgee Catchment Management Authority in NSW. Software was developed in a project funded by the National Action Plan for Salinity and Water Quality and the Natural Heritage Trust by researchers from government agencies in NSW and CSIRO and is designed to be used in conjunction with existing CMA business systems. The system supports the development of catchment scale investment priority models for single or multiple environmental assets developed through a consultative process with CMA and expert agency staff. Catchment priority models facilitate true integrated catchment management by informing the development of strategic catchment plans, as well as providing inputs to assessment of proposals for action at a site level. The project with Murrumbidgee CMA was supported by the compilation of a new vegetation map for the region to enable modelling of priority surfaces for biodiversity conservation, as well as enhanced priority models for water quality, salinity mitigation, afforestation and cultural heritage protection (not shown in this paper). Major 'Ecotender' market-based programs were run throughout the catchment using the system but this paper will focus on the 2010/11 stewardship program to protect and enhance native vegetation in strategic climate change corridors. The software and overall approach proved effective in achieving well-targeted and cost-effective programs for natural resource management. A budget of $\$ 1.5 \mathrm{M}$ was allocated for a 'Climate Change Corridors' program with 76 project proposals received. These were initially assessed based on catchment priority models to reduce the applications down to 55 for site assessment. (The cost for assessment rapidly increases once site assessments have to be made). Of the 55 Site assessments 21 proposals for funding were offered as the best return on investment within the program budget. Success for adoption of this project is related to the CMAs' ownership of every stage in the project development process. They have the flexibility to use their own data and build priority models within a decision support system that allows instant assessments. CMAs can then adjust decisions to achieve the best gains for dollars spent as well as understanding the impacts of actions based on the potential to achieve multiple benefits.
\end{abstract}

Keywords: Decision Support System (DSS), Natural Resource Management (NRM), CMA 
1. INTRODUCTION

SCaRPA is a product of the NSW Government's TOOLS 1 and 2 projects which provided the framework for the development of the Native Vegetation Act regulatory decision support tool, biodiversity forecasting, conservation planning, biobanking and other major NSW government environmental and natural resource management programs. This framework and its associated suite of tools was based initially on concepts developed in the Environmental Services Scheme and further refined in conjunction with and to the specifications set by the NSW Catchment Management Authorities (CMA) and relevant NSW legislation. Knight et al. (2006) outlines that often our science is informative about where one needs to undertake environmental or natural resource conservation, but we are often silent on how to achieve it. SCaRPA is more than a suite of science tools - it is a business system designed to achieve and direct on ground changes. It contains tools for use at both catchment and site scales. The integration of catchment planning and onground implementation decision support tools into a single framework is a key feature of the SCaRPA system (Herron et. al. 2008). It enables the user to develop assessment projects, utilising the full adaptive management approach to guide projects through a robust, auditable and transferable reporting process that meets the NSW Natural Resource Commission and Australian Government reporting needs. Shelton et. al. (2004) indicate that the cost effectiveness of environmental and natural resource management programs is based on leveraging differences, or heterogeneity, between landholders and land management units across catchments or regions, with the aim of reporting the benefits achieved. To achieve this the adaptive management cycle as adopted by the SCaRPA system starts with catchment-scale priority models which can be used as Multi-Criteria Analysis, then scenario modelling, followed by site assessments and finally business evaluation on the cost benefits of the various applications submitted by landholders.

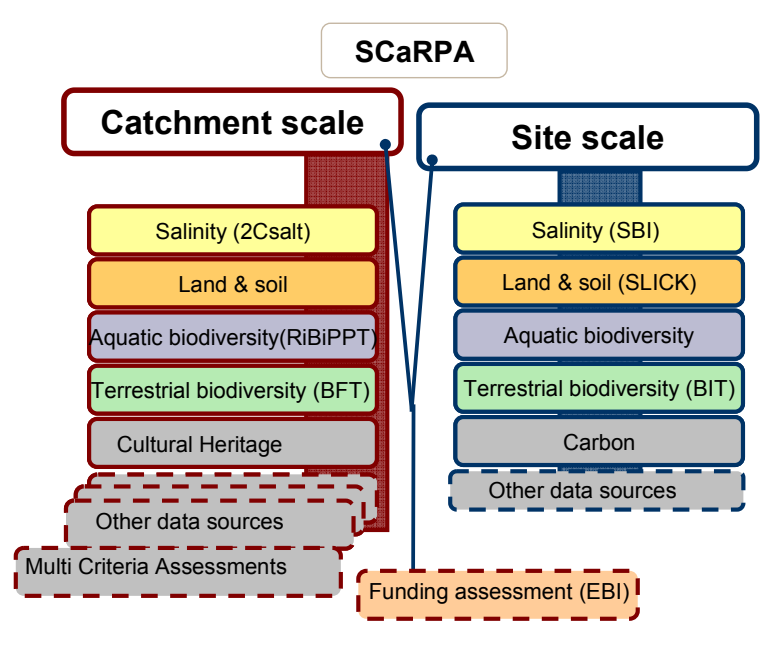

Figure 1. SCaRPA architecture and models.

Figure 1 shows the current Catchment and Site scale models that are actively used and supported throughout NSW within the SCaRPA systems. To date, 8 out of the 13 CMAs in NSW have been utilising the regional priority layers and site assessment tools, often transferring these to their own internal systems, with the Murrumbidgee CMA being the first CMA to embrace the full application including utilising the funding assessment module. One of the strengths of the SCaRPA system is that it is customizable to utilise any source of information in a quasi plug and play environment. These "other data sources" can be either incorporated internally or externally to the SCaRPA system. If CMAs choose not to use the bio-physical tools provided in the framework they replace these with their own tools or models through the other data source options. At the minimum the framework integrates programs into a single framework, but by using the tools within the framework, more scientifically robust assessments can be made as many of the models and tools within and between catchment and site scales are developed from the same scientific foundations. This aids with the multi-criteria assessment to maximise the benefits between assessment themes.

The value of the SCaRPA system is that it provides a framework to identify, with the various science teams and extension officers, where overlaps or gaps in information may occur. In some cases integration overlaps information, in others it may require combining the different modelling sources and techniques.

This paper focuses on the use of SCaRPA in the climate change corridors adaptation stewardship program that was run by the Murrumbidgee CMA in 2010/11. The aim of the program was to protect and enhance native vegetation (habitat) in areas where the CMA has identified important regional corridors. It is viewed that these corridors increase the resilience of the landscape and biodiversity to the effects of climate change and variability. The entire Murrumbidgee catchment was the study area (Figure 2). A map based on an external regional climate change corridors priority model was used to develop the over-arching strategic planning for site selection. Landholders in the CMA region were then invited through local media advertising to apply for funding to undertake works with the CMA. Selected sites that aligned with the regional corridors were then assessed to determine what onground works could be done to achieve the overall aims of the program. These assessments used the site terrestrial biometrics tool called the Biodiversity Incentive Tool 
(BIT) (Wilson et al., 2009). BIT scores determined current vegetation condition and connectivity to the surrounding landscape with proposed management changes (ie weed control, grazing control). The difference between these two scores equated to the biodiversity 'benefit' of the proposal. The site and regional corridor assessments were then brought into the internal business system of SCaRPA where further considerations such as threatened species and land suitability assessments were incorporated into a final environmental benefits index.

\section{METHODS}

The flexibility of the system is demonstrated in the following methods whereby catchment and site assessment tools from various sources are used in the SCaRPA environment to develop the overall assessment criteria.

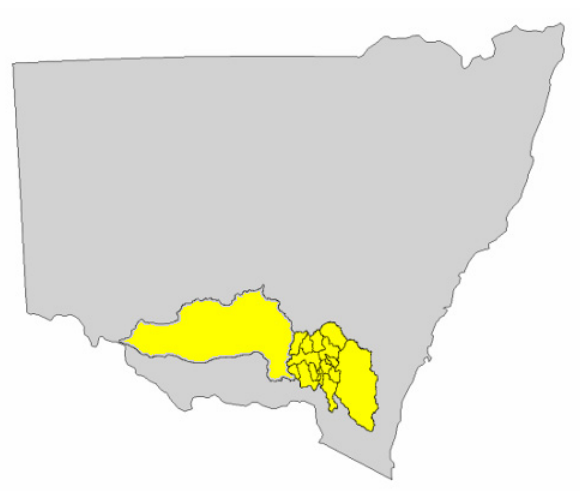

Figure 2. Murrumbidgee catchment within NSW showing major internal catchments. The Climate Change Corridors stewardship program ran across the entire catchment.

\subsection{Environmental benefits assessment of selected sites}

A set of sites were selected and ranked for environmental benefit as follows:

1. The Climate Change Corridors program was advertised and land holders were invited to submit an 'Expression of Interest' (EOI) for project proposal funding, a total of 76 EOIs were received.

2. Sinclair Knight Merz (SKM) were contracted to develop a desktop assessment methodology that ranked EOIs from highest to lowest value. There were two analysis phases, the first phase ranked proposals on a 'landscape connectivity' score derived from the $\mathrm{E}=\mathrm{M} 3 \mathrm{C} 3$ project (SKM, 2009). The 76 proposals were allocated into one of the Very High, High, Medium or Low categories based on the landscape connectivity score. A short list of the 55 most highly ranked proposals was constructed.

3. The Biodiversity Incentive Tool (BIT) was used during field data collection to undertake site assessments of the 55 highest raking EOIs from phase one.

4. These 55 EOIs were then ranked by SKM again in the second phase based on additional criteria, including - proximity to regional corridors, proximity to core corridors, vegetation score, proximity to core vegetation patches, open woodland regional connectivity score, proximity to wetlands, proximity to reserves, proximity to Travelling Stock Routes, proximity to Greening Australia project sites and proximity to Bush Heritage Australia property.

5. An environmental benefits index (EBI) was then constructed using weightings for both catchment scale (SKM score) and site scale (BIT) assessments, together with field assessments made using threatened species and land suitability tools. The 55 short listed EOIs were then ranked on their calculated EBI values and 21 of the most cost effective proposals were selected for funding offers.

\subsection{Catchment scale assessment of environmental benefits from selected sites}

As part of the Murrumbidgee CMA Catchment Action Plan (CAP) Assessment project a number of catchment scale datasets have been developed that allow the benefit of the proposed investment to be modelled at the catchment scale. These included a seamless vegetation map based on the best available mapping and modelled native vegetation condition.

The catchment scale assessment was informed by the findings of the site assessment, collected using the BIT, which were used to update the regional scale spatial data sets used in the modelling. The biodiversity component of the BIT assessment is based on the approach developed by Gibbons et al. (2009) used in the 'BioMetric Tool'. The biodiversity benefit of a proposed action (investment) is calculated as the difference 
between the current (measured) vegetation condition and predicted future condition with the proposed change in management.

The Biodiversity Forecasting Tool (BFT) is used to model how these small site-scale changes influence the status of biodiversity at the catchment scale. This assessment is based on a modelled measure of habitat value, termed the Effective Habitat Area (EHA) which reflects both habitat condition and configuration. Figure 3 illustrates how modelled change in EHA is used to assess indirect as well as direct improvements as a result of site scale NRM investment. This modelling also demonstrates how 'the whole' can be 'greater than the sum of its parts', which is the result of interactions between sites.

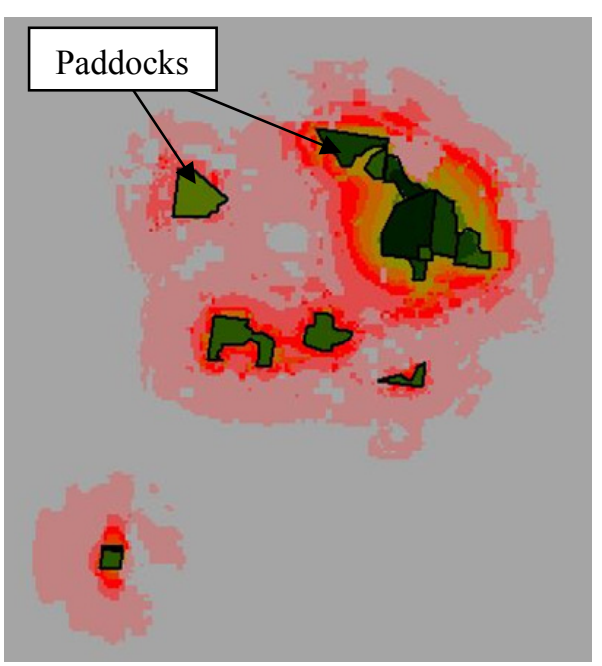

\subsection{Future use of catchment scale prioritisation}

In 2011/12 another Climate Change Corridors program is being run in the Murrumbidgee CMA catchments. This time the full SCaRPA framework, including catchment scale models, is being applied. The following is an outline of the catchment scale assessment methodology which is currently being implemented.

\subsection{Phase 1 - Catchment scale prioritisation}

The development of priority models is based on a simple conceptual model which is similar to the one suggested by McIntyre and Hobbs (2000) for fitting management priorities to landscape condition status, although their terminology differs slightly. In terms of onground works all CMA activities can be grouped into one of the following three broad activity types based on the intended change in natural resource asset condition or extent brought about by the activity:

Figure 3. Graphical illustration of predicted indirect change in habitat value, or effective habitat area, (yellow $=$ large influence through to light red $=$ low influence) as a result of predicted change in native vegetation condition proposed NRM investment sites (darker green = greater improvement in predicted condition change in the paddock).

1. Increasing extent: For areas where the asset is in very poor condition, there are activities to increase the extent of the asset (Figure 4). It is recognised that this is the most resource intensive of the three activity types. McIntyre and Hobbs (2000) refer to this activity as 'reconstruct'.

2. Improving condition: For areas where the asset is in moderate condition both condition improvement and threat mitigation activities can be undertaken (Figure 4). This involves active management of the area (or adjacent/surrounding area) to improve condition. McIntyre and Hobbs (2000) also use the term 'improve' to describe this activity.

3. Mitigating threats: For all examples of an asset, but especially those in high condition, the focus of activities is on mitigating threats that lead to loss of condition (Figure 4). McIntyre and Hobbs (2000) refer to this activity as 'maintaining' condition.

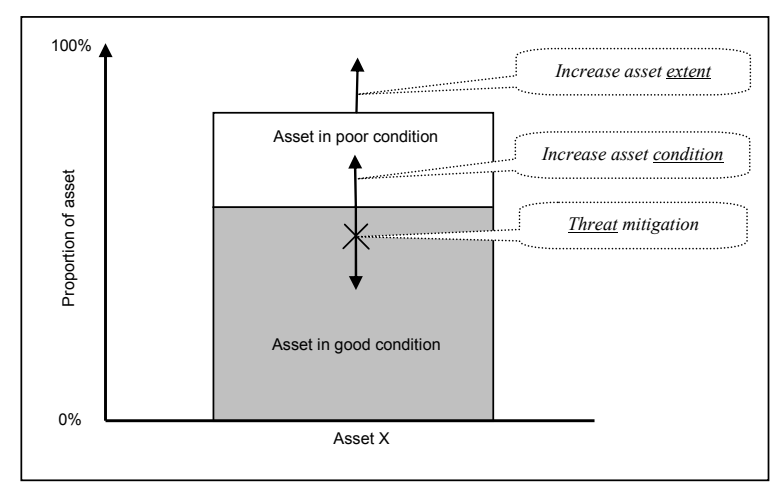

\subsection{Phase 2 - Catchment scale assessment of proposals (EOIs)}

When all the EOIs have been received they are evaluated in a desktop assessment which ranks them in terms of meeting the catchment scale objectives of the Climate Change Corridors program. This ranking is used to decide which EOIs warrant a site inspection and assessment, and those that have other environmental benefits and may warrant further consideration.

Figure 4. Graphical representation of the extent of a hypothetical asset, in both good and poor condition and the three broad types of NRM investment interventions 


\section{6 . Phase 3 - Site scale assessment of proposals}

As much as possible the site assessment will mirror the catchment scale assessment and prioritisation process. In this way the site assessment can be seen as a validation of the catchment scale priority models. A customised version of the BIT is used to undertake the site assessment.

\subsection{Phase 4 - Scoring and ranking all proposals based on catchment and site scale assessments}

The final 'benefit' score assigned to each EOI is made up of site and regional measures. Site measures of vegetation condition and predicted improvement with proposed management can be used in the Biodiversity Forecasting Tool to develop a catchment scale score.

As in the first program the SCaRPA site scale tool will be used to combine scores to calculate an environmental benefit and final ranking.

\section{RESULTS}

\subsection{Environmental benefits and cost-effectiveness}

Cost-effectiveness analysis of the applications reflects the overall environmental benefit achieved combining both site assessments and regional priorities to build corridor linkages against the available investment funds. Figure 5 shows the top 28 EOIs outcomes from the 2010/2011 Murrumbidgee CMA climate change corridors assessment program. The shaded polygon above the zero dollars line represents landholder projects that are predicted to achieve good environmental outcomes and are cost effective. Projects below this line may offer attractive environmental benefits, but at a higher cost and are therefore marginal in cost-effectiveness. Depending on the acceptance of offers by the preferred applicants the next group may also be considered for funding. The projects at the far right of Figure 5 represent landholder projects which do not meet an acceptable level of environmental benefit and would not be recommended for funding under the program. The less cost-effective projects assessed under the program may satisfy the criteria for other incentive programs with different criteria and could be assessed should funding be available. The flexible SCaRPA system allows for this functionality and decision logic.

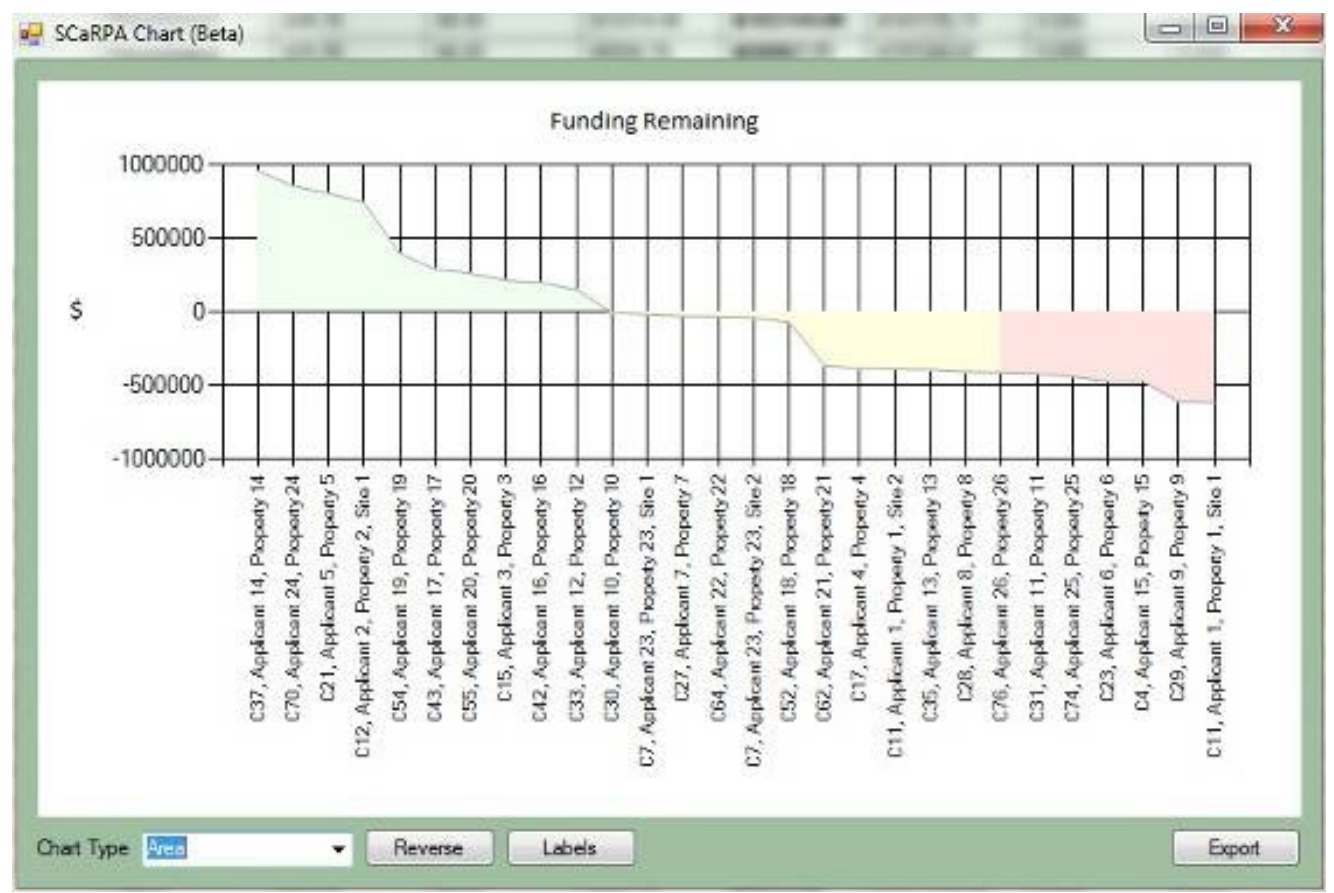

Figure 5. Cost effectiveness of the 2010 - 2011 Murrumbidgee CMA Climate Change Corridors assessment program. 


\section{DISCUSSION AND CONCLUSIONS}

Herron and Cuddy (2008) discussed in detail the pathway for adoption of the SCaRPA system sighting three intrinsic elements needed for a sound decision support system, they described; a design element, which relates to the technical implementation of the system; such as the software architecture, the efficiency and logic of the code, run times and the aesthetic and logic of the interface; a content element, which relates to the data and models needed to inform a decision-making process; and a process element, which translates content into a form for decision-making. More recently Jacob and Snyder (2011) reported on a series of case studies of NRM planning processes and developed a series of six key lessons: These were to 1. Engage the stakeholders and other key individuals early. 2. Earn credibility for the scientific and/or technical tools. 3. Find a good balance between the precision of the tools and their accessibility and utility. 4. Maintain feedback loops throughout the process. 5 . Watch out for exogenous factors that can dramatically impact the planning process. 6. Plan on the process requiring more time than you expect it should.

The delivery of the SCaRPA decision support system discussed in this paper updates the content and process element component identified by Herron and Cuddy (2008) and similar adoption process based on key lessons of Smith \& Snyder (2011). Recent SCaRPA content and process element logic can be summarised in five areas:

The first is relevance. Is there a niche market for a tool to assist a client in decision-making? Although this comment seems trivial and obvious, in practice it is not. Often scientists create their tools and then look for clients to use them.

The Second is workability. Can the tool actually be used within the constraints of available data and is it time-effective in its operation.

The third is flexibility. This is more than a system being flexible to accept any source of data. It also includes the ability to adjust the required amount of decision logic needed to make a decision. Generally regional officers implementing landuse change are time-short and need to judge how much time is needed to genuinely assess a project. Different amounts of effort are needed for different levels of project assessment. This is usually determined by the size of the investment being made.

The fourth is trust. A large investment by regional bodies is needed when they train their operational field staff to learn new assessment tools. They need to know that their investment in your tool will have longevity beyond the bounds of the original project, so they are aware of support and potential enhancement opportunities in the future.

The fifth is reputation. The regional bodies haven't got the resources or time to ensure the tools they are using are credible and defensible so they must rely on the track record, performance and exposure created by the science teams to allow them to make an informed decision. Often having tools that have been endorsed or accredited by other organizations is a good indicator.

The SCaRPA project has developed trust by bringing the core programming and science abilities into one group. This demonstrates a clear sense of ownership and support to the client. The project has continued to operate on a user pays approach, not major grant funding. This means the tools that have been successful to date in the SCaRPA framework are those that the regional bodies trust, and wish to invest in because they have relevance to their needs and reporting structures. The tools in the SCaRPA system have good relevance and workability and this was achieved by strategically letting the regional bodies design the concepts for the tools. These concepts usually reflected the data resourcing available. Flexibility of the SCaRPA system is achieved in two parts. Firstly the system accepts data or information from any source and being able to transparently link its usage to decision making. Secondly is the ability for the system to adjust the level of assessment needed to make a funding assessment. For example in the SCaRPA system if it's a small grant often just having a few criteria showing a transparent logic is enough for auditing procedures, whereas if it's a larger program then more detailed consideration using objective decision tools is needed. For very large programs such as Eco-tenders, mechanisms to capture the decision process is often assessed by independent panels, so a different approach to information management is required again. Reputation is earned and hard to judge. For the SCaRPA team and the active tools within its framework, work is developing by word of mouth from previous clients reporting satisfaction. So for the SCaRPA team our reputation is showing signs of growing. 
Summerell et al., Implementing decision support for Natural Resource Management agencies

\section{ACKNOWLEDGMENTS}

The Office of Environment and Heritage NSW and the Future Farm Industries CRC for engaging this project. The Murrumbidgee CMA Board for endorsing the project, National Action Plan for Salinity and Water Quality and the Natural Heritage Trust.

\section{REFERENCES}

SKM (2009). Ecosystems = Murray Mount to Mountains Climate Change Corridors Program [E=M3C3]: Background Literature Review and Model Methodology.

Shelton, D., Langston, A., and Whitten S.M. (2004). Market Based Instruments, A rapid assessment technique for identifying the potential for MBI application. Rural Industries Research and Development Corporation. ISSN 1440-6845.

Gibbons, P., Briggs, S.V., Ayers, D., Seddon, J., Doyle, S., Cosier, P., McElhinny, C., Pelly, V. and Koberts, K. (2009). An operational method to assess impacts of land clearing on terrestrial biodiversity. Ecological Indicators. 9, $26-40$.

Knight, A.T., Richard, M., Bruce and Campbell, M. (2006). An Operational Model for Implementing Conservation Action. Conservation Biology 20(2), 408-419.

Jacob, S. and Snyder, K (2011). Bridging the Divide Between Science and Planning: Lessons From Ecosystem-Based Management Approaches to Local and Regional Planning in the United States. A Place Matters Institute Publication. Online: (Accessed October 10 ${ }^{\text {th }}, 2011$ ).

http://placematters.org/sites/default/files/reports/2010/11/Bridging\%20the $\% 20$ Divide $\% 20$ \%20March\%202011.pdf

Bureau of Rural Sciences (2009). Multi-Criteria Analysis Shell for Spatial Decision Support MCAS-S V2.1 user guide, October 2009. Australian Government. Online: http://www.brs.gov.au/mcass (Accessed on February 1st, 2011).

Herron, N.F., and Cuddy, S. (2008). DSS Success Measures: Evaluating the SCaRPA DSS. iEMSs 2008: International Congress on Environmental Modelling and Software Integrating Sciences and Information Technology for Environmental Assessment and Decision Making 4th Biennial Meeting of iEMSs, http://www.iemss.org/iemss2008/index.php?n=Main.Proceedings

Sànchez-Marrè M., J. Béjar, J. Comas, A. Rizzoli and G. Guariso (Eds.) International Environmental Modelling and Software Society (iEMSs).

Herron, N.F., Barrett, T.W. and Cuddy, S.M. (2008). Linking catchment environmental planning to

on-ground investment: the SCaRPA DSS, iEMSs 2008: International Congress on Environmental Modelling and Software Integrating Sciences and Information Technology for Environmental Assessment and Decision Making 4th Biennial Meeting of iEMSs, http://www.iemss.org/iemss2008/index.php?n=Main.Proceedings

M. Sànchez-Marrè, J. Béjar, J. Comas, A. Rizzoli and G. Guariso (Eds.) International Environmental Modelling and Software Society (iEMSs).

McIntyre, S. and Hobbs, R. (2000). Human impacts on landscapes: Matrix condition and management priorities. In JL Craig, N Mitchell and DA Saunders (Eds), Nature Conservation 5: Nature Conservation in Production Environments. Surrey Beatty and Sons, Chipping Norton NSW, pp. 301-307.

Wilson, G., Briggs, S., Doyle, S., Cummings, J. and Petersen, P. (2009). Biodiversity Incentive Tool Version3 Extract of Operational Manual June 2009, NSW Department of Environment and Climate Change. Online: Contained in the software install files downloaded from http://www.pp.com.au/pp/bit.html (Accessed on July 15th 2011). 